\title{
Mental health courts: process and outcomes John Petrila
}

\author{
Address: University of South Florida, 13301 Bruce Downs Blvd, Tampa, FL 33612, USA \\ from WPA Thematic Conference. Coercive Treatment in Psychiatry: A Comprehensive Review \\ Dresden, Germany. 6-8 June 2007 \\ Published: 19 December 2007 \\ BMC Psychiatry 2007, 7(Suppl I):S26 doi:10.1 186/I47I-244X-7-SI-S26
}

This abstract is available from: http://www.biomedcentral.com/I47I-244X/7/SI/S26

(c) 2007 Petrila; licensee BioMed Central Ltd.

Mental health courts are the most recent development in therapeutic courts [1]. While mental health courts vary in their characteristics, they rest on the assumption that creating access to treatment for defendants is an important strategy in reducing recidivism. Mental health courts differ from traditional criminal courts in a number of important ways. The most significant is that the judge and lawyers do not rely on the adversarial model of fact-finding, but seek instead to act in concert to achieve a therapeutic outcome for the defendant. The number of courts continues to grow rapidly, despite the fact that there is comparatively little research regarding their effectiveness. This presentation will discuss a) similarities and differences in existing mental health courts, b) the processes by which the courts identify and dispose of individual cases, c) results from the outcome studies that do exist, and d) and emerging research, policy, and practice questions.

\section{References}

I. Petrila J: An introduction to special jurisdiction courts. Int J Law Psychiatry 2003, 26:3-12. 